\title{
The Teaching Strategies of Colleges for Public Art Class in the "Era of Contest for Attention"
}

\author{
Jieen Guo \\ School of Art and Design \\ Xi'an University of Technology \\ Xi'an, China
}

\begin{abstract}
In the era full of mobile network and mass information, the value of public art class in colleges is being affected by the convenient mobile network information. Compared with the network message, can the traditional class teaching retain its original advantages yet? In the era, class content has to compete with the mobile network, and what strategies we should take to improve the class teaching of public art in colleges becomes an issue to be discussed in this paper.
\end{abstract}

Keywords—public art; class; teaching

\section{INTRODUCTION}

For the young people growing in the Internet age, it is an easy thing to take access to information, and by slightly clicking in the phone screen with fingers, they can get the information they want immediately. In today's college class, the things or concepts just mentioned by teacher may be quickly read throughout by students in the class through the form of Baidu Encyclopedia. Just a mobile phone brings convenient, plentiful and mass network information to the students in the class silently and quietly, which is attracting students' attention all the time, contesting with the regular, serious and orderly class teaching. Looking around, most of the students in class are often lowering their head but few raise their head, and fewer and fewer students can focus on listening to class in dozens of minutes. In the public art class of colleges and universities, the traditional teaching method of "You teach, I listen" with the platform background of playing PPT seems to have gone for ever.

In the past, the class of public art in universities was mostly based on the content of comprehension and appreciation, and the teachers introduced the art knowledge to the students to improve the students' aesthetic cognition. However, in the era of mobile network and mass information, almost any existing art appreciation content can be obtained by "search", which makes the authority of teachers in unilaterally providing the content and the value of class teaching are challenged. When the concepts, principles, methods and even a variety of examples and views can be obtained only by clicking the screen at your fingertips, can we ensure students listen to the class of fixed contents for continuous 45 minutes? Does such a class have value or interest? Compared with the network information, does the class have advantages? Can the class teaching of public art retain its original value? What strategies do we have to make class teaching get remarkable effectiveness and keep up with the times?

\section{THE LiMITATIONS OF WEB BROWSING AND THE ADVANTAGES OF ClASSROOM TEACHING}

\section{A. The Limitations of Network Information: Fragmented Information Easily Leads to the Settlement of Shallow Knowledge}

The effect of teaching activities is reflected by the development of students after learning, while the rapid and effective development of students often depends on the accumulation of orderly and incessant learning and establishment of the knowledge system, rather than the receipt of fragmented information in a short time. The accumulation of a certain kind of knowledge or certain ability, has the features of linear development and gradual consolidation to a large extent, which not only needs the initial interest of learners but also requires the continuous and active promotion of students in their study. However the network message is mass, mixed and scattered, and for beginners, it is difficult to identify the materials suitable for their learning stage. Network information appears to be plentiful, and if the learners only make scattered browsing, they will achieve only the comprehension of fragmented knowledge, which is far from the real mastery and application of knowledge. Additionally, network information has the negative impact, because massive fragmented information easily distracts the attention of learners, cuts off the in-depth thinking and produces the feint of information saturation, so as to make learners satisfied with the shallow access.

\section{B. The Advantages of Classroom Teaching: Classroom Teaching Have A Comprehensive Interactive Feature}

Teaching activities are not unilateral, but bilateral between teachers and students. In the process of teaching, teachers guide students to learn according to the law of knowledge, in which teachers play a leading role and students follow the guide of teachers and apply their initiative in learning. Additionally, in the individual learning process, students are often affected by the group performance in the class, and the performance of others and the feedback of surroundings will produce a certain impact on the individual learning enthusiasm and effect of students. If the teaching is arranged reasonably and guided 
properly, this mutual feedback can often achieve positive promotion. In this circumstance of common learning, good and direct feedback effect will produce between teachers and students and between student groups, which is difficult to achieve by the individual unilateral network reading.

\section{THE CHARACTERISTICS OF STUDENTS' LEARNING IN CLASS}

\section{A. Students Have Active Selectivity in Their Learning}

Only when the knowledge and skills taught by teachers, as well as the guidance and inspiration for students, must be thought independently, comprehended and applied by students, can they mastered really by students. Whether students treat their learning actively or not will greatly impact their results of learning. In all class teaching, the students with subjective interests are always able to actively find and solve their problems in their learning, so as to obtain better learning effect. If the instructional design of a course does not cause students' interest in actively participating in learning activities, the course will produce very limited effect.

\section{B. Students May Have Different Learning Incentives}

It is the necessary part of a good teaching experience design to understand the students' thinking way. The learner's sense of accomplishment comes from the effectiveness of learning, but their incentives of learning may be different. There are intrinsic incentive and external incentive. The students with intrinsic incentive have their learning impetus come from their interest or their needs to solve a specific problem, while the students with external incentive have their learning impetus come form external rewards and punishment, so the external factors will directly impact their learning goal and learning activity, such as easy access to credit hours or qualification certificate. In the actual learning, students may have both intrinsic and external incentives and the proportion of the two kinds of incentives may change at the different stages of learning. The specific course theme and the learning environment both may affect the student's learning incentives.

\section{The Cognitive Ability and Cognitive Characteristics of Students Are Subject to Their Physical and Mental Development Level}

Learning is the cognitive activity of learners, and students' learning follows a certain cognitive law, which is first presented by that individual awareness is subject to the physical and mental development level. Different age stages, different educational background, and even different environmental factors, will affect the objective level of physical and mental development of students. Teaching activities must be carried out according to learners' physical and mental development level and their cognitive characteristics, the teaching objectives and the teaching contents and even the teaching methods should be determined according to the actual conditions of learners. At the stage of college, students have matured physical and mental development, strong cognitive ability, active thinking, quick comprehension of information, good ability of acceptance. On the other hand, the negative impact is mainly resulted from their experienced education way over a long period of time. Since their childhood, they experienced universal and longterm "recitation-type" education, making them form a thinking habit of passive acceptance. Most students are lazy in thinking about the given results, and the easy access of network information makes the lavishment of non-intellectual "copytype" learning exacerbated. In the current study of college course, everywhere can be seen the direct and convenient copy and paste, without thinking; fewer and fewer students are willing to actively make deep thinking, errata analysis and pay more energy to complete the learning. In the case of no intrinsic incentive of learning, students have the habits to choose easy task and fence with difficult task, generally expecting immediate achievements by their attempt, being tired of repeatability of difficulty, so as to blench before the difficulties.

\section{THE StRATEGY IMPROVEMENT OF ClASS TEACHING}

After clearing the comparative advantages of classroom teaching in organization, as well as the main features of students in learning, teachers can attempt to adjust the teaching strategies pertinently to improve their teaching methods, call back the attention of students from the phone screen, rebuild the effect and value of public art class teaching.

\section{A. Optimize the Teaching Content, Inspire Students' Learning Initiative}

Through the exchange between teachers and students, we can understand the purpose of students for learning and their troubles in the learning of specific courses. Students select this course of public art for a clear purpose of learning or for a vague follow of main trend? In addition to the credits, what kind of promotion do they want by the study of art course? The enhancement of the link between the course content and the real experience can help more students build intrinsic incentive of learning. When specific cases and questions are directly linked to the real life, students' interest in learning will be enhanced effectively very much. Such as a familiar popular aesthetic phenomenon, we require students study the social significance behind the phenomenon, study how it is generated, and study how a popular aesthetic fashion affects their daily life? In teaching, we should avoid too much theory and background knowledge, instead we should begin the specific issues and make students have interest and further guide students to actively participate in learning activities.

\section{B. Make Good Use of Network Resources, Change the Fight into Supplementary}

In the era of mobile network, people are accustomed to the daily intensive, quick, short and visual information. The duration of students to pay attention to a message is related to the frequency of information and the appearance way of information. The traditional teaching method of description type has static and less information and single form, so it has been difficult to continue to obtain the attention of students. We can use some more interesting and fast-paced way, such as short video, to introduce academic knowledge. Teachers can add rich and diverse online resources into the class content, e.g. we can use movies, animation, cartoon and other lively 
expression way to present the story behind the works of art. Teachers can also use MOOC, WeChat and other network platform to carry out the teaching links such as content release, problem interaction and questionnaire collection. The flexible use of network resources and network tools can broaden the boundaries of the class, improve the occasion, and change the mobile terminal that draws students' attention into a supplementary tool of teaching.

\section{Reasonably Set Active Tasks, Increase the Sense of Achievement from Learning}

As a designer of classroom teaching, teachers should build a pleasing learning process. When students actively participate in the learning process and continuously receive the positive feedback, they will be more willing to learning. Through the design of teaching part, students learn and make practice, rather than a simple passive listening, which will inspire students to make better cognition. For example, when introducing the painting art, we can organize students to copy the classic works so as to deepen their understanding of the painting, and we can also make students express their thoughts and feelings through personal creation, so as to appreciate the essence of artistic creation. Teachers should change the stereotyped teaching methods, create a relaxed classroom atmosphere, apply practice and self-assessment by dint of task design, to make students aware of their ability and make them actively learn.

Teachers can divide the teaching objectives into a series of small tasks of stage, and distribute it to students step by step. In the task design of each stage, we must fully consider the actual level of students and appropriately control the difficulty of learning content. Appropriate difficulty, means the task should have a certain challenge for students, they must pay efforts to complete it but not be unable to complete due to their deficiency of knowledge. Students will have a sense of accomplishment after completing the appropriate task by their efforts, but too difficult task design will damage the student's confidence, causing their boredom of learning. The initial task should not be over time-consuming but should be appropriate for students to complete for a short time in class and to get feedback in class. Through the guidance, after completing the learning tasks of stage, students will immediately get structural experience and increase their self-confidence of learning. In the interval between staged tasks, we should also give students the time to rest.

The feedback on the task is as important as the task, and we should give students timely recognition and encouragement and pointed out the main problem, which can help students successfully acquire learning content in a reliable way. When the individual student has troubles, teacher should provide special assistance or use demonstration to guide the student. In the feedback on task, we can also give full play to the group circumstance advantage of classroom teaching, form a drive among students through their experience sharing, and further create a good learning atmosphere.

\section{CONCLUSION}

The traditional class must correctly treat the "era of contest for attention" in the impact of mobile network information, and the public art class teaching in colleges and universities must adjust the strategies to adapt to the change. Teachers should understand and follow the rules of students' learning, conform to the characteristics of information dissemination and media in the era of Internet, optimize the teaching content, improve teaching methods, give full play to the advantages of class teaching in the scene and organization, build an attractive learning process through curriculum design and effective guide, so as to reshape the effect and value of class teaching. With the timely and appropriate development of teaching methods, the boundaries of class can be broadened and the conflict between inside and outside the classroom can also be changed into a parallel and correlative source of knowledge.

\section{REFERENCES}

[1] Zhang Tianbao. Subjectivity Education [M]. Beijing: Education Science Press, 2001: 71-84.

[2] Julie Dirksen. Cognitive Design: the Art of Improving the Learning Experience [M]. Beijing; Machinery Industry Press 2012: 20-30. 